\title{
Optimized Gas Pricing Policy to Have Maximally Peak Shaving
}

\author{
A.Sheikhi, M.Khosravi ,B.Mozafari, A.M.Ranjbar, A. Hajjam
}

\author{
Department of Electrical Engineering \\ Sharif University of Technology \\ Tehran, Iran \\ Phone/Fax number: 0098912 6613840,e-mail: sheikhi@ee.sharif.edu, khosravi@ee.sharif.edu, mozafari_babak@yahoo.com, \\ ranjbar@sharif.edu,hajjam@ee.sharif.edu
}

\begin{abstract}
Today pricing policy in the electricity network is an effective way to oblige users to change their consumption during peak hours. At the same time by increasing distributed energy resources like Combined Heat and Power (CHP) and also gas network penetration level in huge areas it will be more attractive to use gas price as another motivated factor to alter electricity consumption curve. In this article, based on energy hub concept, an optimization approach related to the power dispatch through an energy hub is simulated and consequently an effective pricing policy of natural gas, to have a maximally electricity load shaving, is determined.
\end{abstract}

\section{Key Words}

peak shaving, natural gas pricing policy, energy hub, optimal operation, Combined Heat and Power (CHP)

\section{Introduction}

Today, small-scale microturbines and other distributed generation plants are used increasingly [1, 2]. Microturbines are providing electricity and thermal energy at the same time, thus using natural gas with a higher overall efficiency compared with single gas turbines or hot water gas boilers. As gas-fired power stations establish a connection between the electrical and chemical network, certain interchangeability as well as a certain redundancy are being introduced into the system [3, 4]. During peak hours it might be financially attractive to generate electricity from gas instead of consuming directly from the electrical network [5]. Therefore it is expected that peaks from the electrical network will be moved to the gas network, resulting in a more intensively and differently used gas network. When considering hot water boilers or combined heat and power (CHP) similar relations and dependencies can be found between thermal network and electrical or chemical networks.

Hence, On the contrary In the past that efforts focused on the operational optimization of systems employing only one form of energy $[6,7,8]$ recent research effort is addressing the integrated control of combined electricity and natural gas systems $[9,10,11,12]$. Different approaches have been developed and used for various purposes.

While approximated flow models are used for instance in [13] for optimizing the flows through an energy supply chain, [14] and others employ detailed steady state power flow equations for natural gas and electricity appropriate for dispatching a real system.

Based on the concept of energy hubs [15] it enables simple analysis of couplings and interactions between the natural gas and electricity infrastructures [16]. The approach presented in this paper aims at a general modeling and optimization framework for energy systems including multiple energy carriers, e.g. gas and electricity, and also their environmental effects. By means of this model and represent an appropriate objective function the paper proposed an effective way to reduce consume of electricity supply in the peak time duration to have a maximally flat load curve by determining a policy for natural gas pricing.

This paper is organized in six sections. After this introduction, the energy hub concept is presented in Section II. Based on this concept, the mathematical model of the considered two carrier system is given in Section III. Exciting electricity and natural gas pricing policy is mentioned in section IV. Main problem, objective function and a proposed pricing policy are then investigated in Section V. Finally, Section VI summarizes and concludes this paper.

\section{Energy Hub Modelling}

Some conceptual approaches for an integrated view of transmission and distribution systems with distributed generation have been published. Besides "energy-services supply systems"[17], "basic units"[18], and "micro grids"[19], so-called "hybrid energy hubs", are suggested, where the term "hybrid" represent the use of multiple energy carriers[5,10,11]. An energy hub is considered a unit where different energy carriers can be converted, conditioned, and maybe stored. It represents an interface between different energy infrastructures and/or loads. Energy hubs consume power at their input ports which is connected to, e.g. electricity and natural gas infrastructures, and prepare certain required energy services such as electricity, heating, cooling, and compressed air at their output ports [10].

Energy hubs include two basic elements: direct connections and converters. Direct connections are used to deliver an input power to the output without converting. Converter elements are used to change carriers into other forms or qualities. Some of these convertors to mention are gas turbines, combustion engines and fuel cells. Figure 1 demonstrates an example of an energy hub. 
The components within the hub may create extra connections between inputs and outputs. For instance, the electricity load connected to the hub in Figure 1 can be met by consuming all power directly from the electricity grid or generating part or all of the required electricity from natural gas. This redundancy in supply results in a significant benefit, which can be achieved using energy hubs: Reliability of supply can be enhanced from the load's perspective because it is not completely dependent on a single supply.

From a system point of view, combining and coupling different energy carriers show a number of potential benefits over conventional, decoupled energy supply.

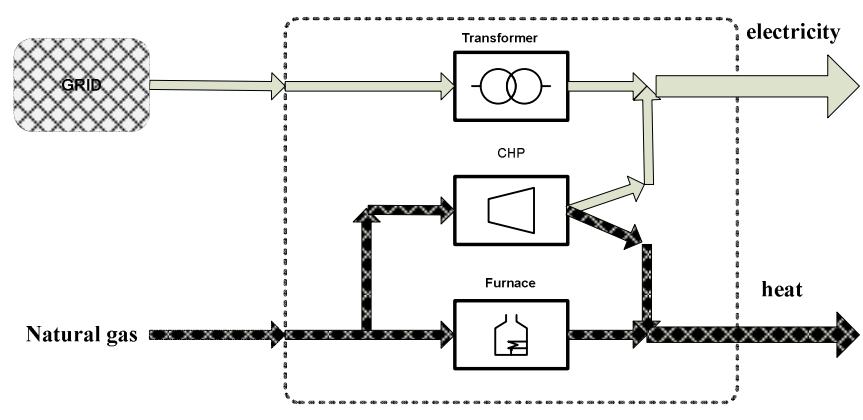

Fig. 1. Example of an energy hub that contains an electric transformer, a CHP and a gas furnace

The energy hub is an archetype with no limitations to the size of the modeled system. Single power plants or industrial buildings as well as bounded geographical areas such as entire towns can be modeled as energy hubs. The model of the system is formulated below.

In the system under study, the energy hub represents a general consumer as a household which uses both electricity and gas. The hub is connected to a large gas network and the electricity network.

The hub consumes electric power $P_{e}$ and gas $P_{\mathrm{g}}$ and provides energy to its electric load $L_{\mathrm{e}}$ and its heat load $L_{\mathrm{h}}$. The hub contains converter devices in order to fulfill their energy load requirements. For energy conversion, the hub contains a CHP device and a furnace. The CHP device couples the two energy systems at the same time that produces electricity and heat from natural gas. Depending on the prices of energy and load profiles, the CHP device is utilized differently. At high electricity prices, the electric load is supplied by CHP more than normal times. Thereby produced heat is then used to supply the thermal load. At low electricity prices, the electric load is rather supplied directly by the electricity network and the gas is used for supplying the thermal load via the furnace or boiler. Hence, there are several ways in which electric and thermal load demands can be fulfilled. This redundancy increases the reliability of supply and simultaneously provides the possibility for optimizing the input energies, e.g. using criteria such as cost, availability, emissions, etc.

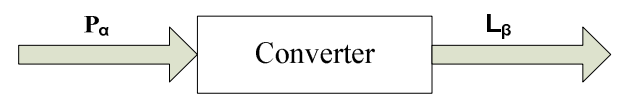

Fig. 2. Model of power converter
Consider a converter device as indicated in Fig (2) that converts an input energy carrier $\alpha$ into $\beta$. Input and output power flows are not independent; we consider them to be coupled

$$
\mathrm{L}_{\beta}=\mathrm{c}_{\alpha \beta} \times \mathrm{P}_{\alpha}
$$

Where $\mathrm{P}_{\alpha}$ and $\mathrm{L}_{\beta}$ are the steady state input and output powers, respectively $\mathrm{c}_{\alpha \beta}$ is the coupling factor; it defines the coupling between input and output power flow. For a simple converter device with one input and one output, the coupling factor corresponds to the converter's steady state energy efficiency. Fig(2).

A general model covering all types of couplings can be stated that all power inputs $\mathrm{P}_{\alpha}, \mathrm{P}_{\beta}, \ldots, \mathrm{P}_{\omega}$ and outputs $\mathrm{L}_{\alpha}, \mathrm{L}_{\beta}, \ldots, \mathrm{L}_{\omega}$ in vectors and, respectively, enables the formulation of multiinput multi-output power conversion analog to (2)

$$
\left[\begin{array}{l}
\mathrm{L}_{\alpha} \\
\mathrm{L}_{\beta} \\
\cdot \\
\cdot \\
\cdot \\
\mathrm{L}_{\omega}
\end{array}\right]=\left[\begin{array}{cccccc}
C_{\alpha \alpha} & C_{\beta \alpha} & \cdot & \cdot & \cdot & C_{\omega \alpha} \\
C_{\alpha \beta} & C_{\beta \beta} & \cdot & \cdot & \cdot & C_{\omega \beta} \\
\cdot & \cdot & \cdot & & \cdot \\
\cdot & \cdot & & \cdot & & \cdot \\
\cdot & \cdot & & & \cdot & \cdot \\
C_{\alpha \omega} & \cdot & & & & C_{\omega \omega}
\end{array}\right]\left[\begin{array}{l}
\mathrm{P}_{\alpha} \\
\mathrm{P}_{\beta} \\
\cdot \\
\cdot \\
\cdot \\
\mathrm{P}_{\omega}
\end{array}\right]
$$

\section{Electricity and Natural Gas Pricing Policy}

At the retail level, market participants are exploring a variety of program designs for shifting customer usage from highpriced on-peak hours to lower-priced off peak hours, in order to dampen the impact of price spikes and generally reduce the cost of procuring power supply from competitive markets. For larger commercial and industrial facilities with hourly metering, "demand-response" or "peak-shaving" programs typically involve customer curtailment of load at specific times of the day, either by request of that customer's retail power supplier or in response to real-time price signals.

Electricity pricing policy consideration is an effective way to reduce electricity demand in peak hours. It means that by increasing electricity price in peak hours consumers are provoked to decrease their consumption and shift it to the times that the electricity has a lower price. Thus, implementing this policy reduces electrical load demand in peak hours effectively.

Nowadays by growing natural gas networks in vast areas, and incentive for that is given by the increasing utilization of gasfired and other distributed generation, especially co- and tri generation [20], thus natural and electricity gas are not considered independent and their prices have obvious effects on each other but up to now this mutual effect has been not investigated well.

During peak hours it might be financially beneficial to generate electricity from gas by distributed generation instead of consuming directly from the electrical network, then it is 
expected peaks from the electrical network will be moved to the gas network, resulting in a more intensive and different used gas network.

In the next section a novel method is presented on the gas pricing policy which considers the gas price as a variable price not a constant value. This condition, results electrical consumption curves to alter significantly and can be used for adjusting electricity consumptions.

The main contribution of this paper is to find an appropriate gas price to have a rational peak shaving [18] by regarding economical aspects. This condition makes gas price changes hourly and results electrical consumption curves alter significantly. Hence, gas price can be used to adjust electricity consumption.

\section{Proposed Optimization Methodology}

Pricing policy in the electricity network is a very effective way to oblige users to change their consumption during peak hours. On one sight expanding natural gas network in vast areas and at the same time increasing use of co- and trigeneration units makes it more attractive to use gas price as another motivated factor to alter consumption curves.

In this section, an optimization approach in accordance with the power dispatch through a city as an energy hub is cited and discussed.

The objective function not only contains user benefits but also considers peak shaving as an important factor in power systems.

In this study all the co generators, boiler and transformers in the city are modeled respectively by a CHP, a boiler and a transformer. The natural gas and electricity transmission loss are negligible.

Main variables in the mentioned objective function are input power $\left(\mathrm{P}_{\mathrm{e}}\right.$ and $\left.\mathrm{P}_{\mathrm{g}}\right)$, dispatch factor and the gas price.

Feasible region of optimization problem is defined by equality and inequality constrains. Equality constrains are given by the equation that describes the power flow in the hub and the mean value of gas price. Inequalities arise from limitation of power converter capacity and dispatch factor. Minimizing the following objective function results the best natural gas pricing policy, electricity and natural gas consumption and also dispatch factor by considering the peak shaving as a significant factor. Consequently electricity consumption curve approaches a straight line.

$$
\begin{aligned}
& L_{e}=\eta_{e e} P_{e}+\gamma \eta_{g e}^{C H P} P_{g} \\
& L_{h} \leq\left((1-\gamma) \eta_{g h}^{F}+\gamma \eta_{g h}^{C H P}\right) P_{g} \\
& P_{g}^{\min } \leq P_{g} \leq P_{g}^{M a x} \\
& P_{e}^{\min } \leq P_{e} \leq P_{e}^{M a x} \\
& 0 \leq \gamma \leq 1
\end{aligned}
$$

$$
\begin{aligned}
& \operatorname{Min}\left\{\sum_{n=1}^{24}(1-\alpha)\left(P_{e}(n) e(n)+P_{g}(n) g(n)+P_{e}(n) \chi_{e}+P_{g}(n) \chi_{g}\right)+\right. \\
& \left.\alpha \times \min \left(P_{e}(n)\right)\right\}
\end{aligned}
$$

Where:

$\mathrm{L}_{\mathrm{e}}$ is electrical load

$\mathrm{L}_{\mathrm{h}}$ is heating load

$\gamma$ is called dispatched factor, it is defined as a dispatch of the natural gas input to the CHP and the furnace.

$\eta_{e e}$ is the transformer efficiency

$\eta_{g h}^{F}$ is the furnace efficiency

$\eta_{g e}^{C H P}$ is the electrical efficiency of CHP

$\eta_{g h}^{C H P}$ is the heating efficiency of CHP

On the other hand today the threat of global warming and climate change created worldwide concern. This translated into many countries signing agreement such as Kyoto in order to reduce greenhouse gas emission. Hence, CO2 emission consideration is highlighted as one of the effective factor on power generation. For modeling this factor $\chi_{e}$ and $\chi_{g}$ are introduced. These parameters convert $\mathrm{CO} 2$ emission of electricity and natural gas, as the energy hub input, to the dollars.

Based on the social cost of carbon emissions, that an optimal price of carbon is around $\$ 30$ (US) per ton $(0.03 \$$ per $\mathrm{Kg})$ and will need to increase with inflation and the national average output rate for all petroleum-fired generation is averagely 0.9 $\mathrm{Kg} \mathrm{CO} 2$ per kilowatt-hour and the output rate for $\mathrm{CO}_{2}$ from natural gas fired plants is $0.58 \mathrm{Kg} \mathrm{CO}_{2}$ per kilowatt-hour. the optimal price of carbon is $0.027 \$$ per $\mathrm{KWh}$ for using electricity $\left(\chi_{e}\right)$ and is about $0.0175 \$$ per KWh for using natural gas $\left(\chi_{g}\right)$ as energy hub input.

$\mathrm{g}(\mathrm{n})$ and $\mathrm{e}(\mathrm{n})$ are prices of natural gas and electricity for consumers in $\$$ per KWh.

$\alpha$ is the peak shaving weighting factor. It can be adjusted between 0 and 1 :

- $\alpha=1$ yields maximal peak shaving

- $\alpha=0$ yields minimal energy cost

Variation of the factor $\alpha$ will result in an increasing of one and a decrease of the other objective function component, which means that criteria are conflicting. in order to achieve well distributed solution among the $\alpha$-range, an adaptive algorithm is employed.

\section{Simulation Results}

In this section a city was considered as an energy hub system and gas pricing policy was put forward for this city. The hourly electrical and heating consumption for this city is depicted in figure 3.

The main method which is used in the aforementioned optimization problem is based on a two-step hybrid algorithm idea.

In the first step an approximate optimum solution as an initial point for the next step of the hybrid algorithm is found using a simple but time-consuming Genetic Algorithm. In second step, since the cost function and all the constraints in the problem are in quadratic form, the optimal solution can be found with the help of Steepest Descent algorithm, based on the achieved sub-optimal solution of the first step. 


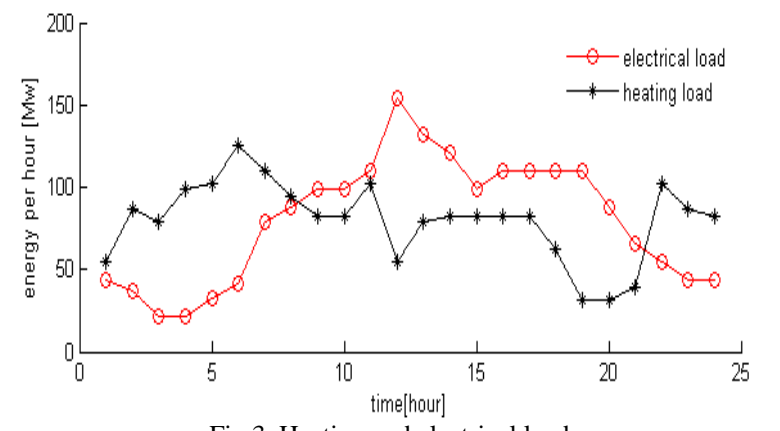

Fig.3. Heating and electrical load

Simulation results demonstrate the effect of this pricing policy to have a maximally peak shaving.

In figure 4 gas price is considering fixed and equals 2 cent per kwh by $\alpha=0$.

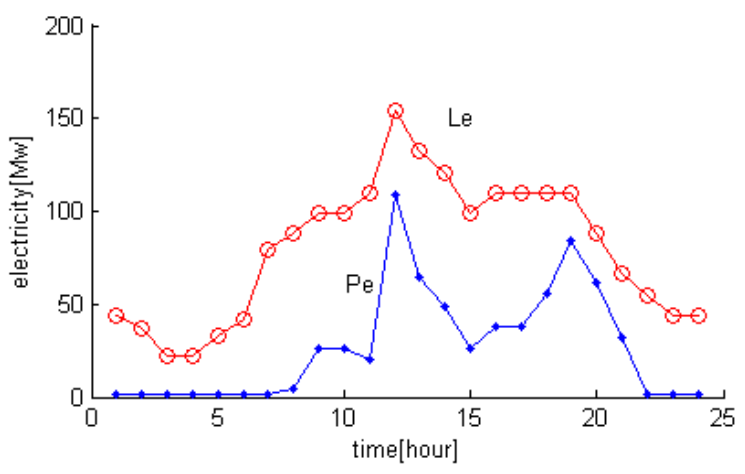

Fig.4. Pe and Le in when gas price is fixed

In the second case by including $\alpha$ in the objective function and considering following constrains for hourly gas prices:

1. Max gas hourly gas price $=3 \mathrm{c} / \mathrm{kwh}$

2. Minimum gas hourly gas price $=1.5 \mathrm{c} / \mathrm{kwh}$

3. Average of gas price $=2 \mathrm{c} / \mathrm{kwh}$

4. Energy consumption price has to be equal in both case.

Then the best gas price by considering peak shaving to have minimum energy price is depicted in figure 5 .

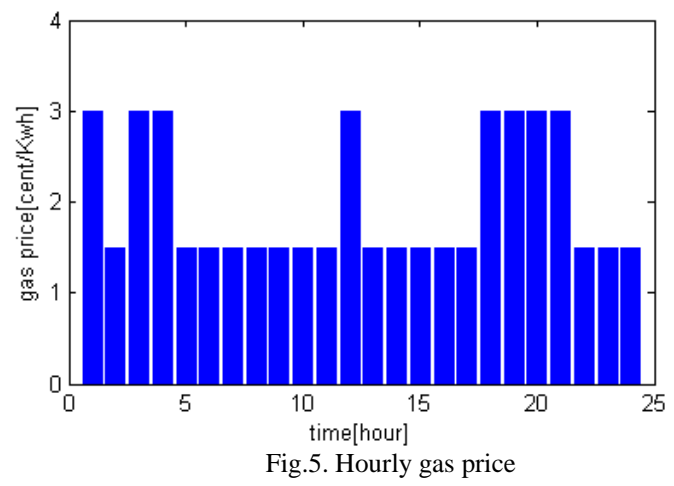

By above assumptions $\alpha=0.233$.

In the figure $6 \mathrm{P}_{\mathrm{e}}$ after and before including peak shaving in the objective function are demonstrated.

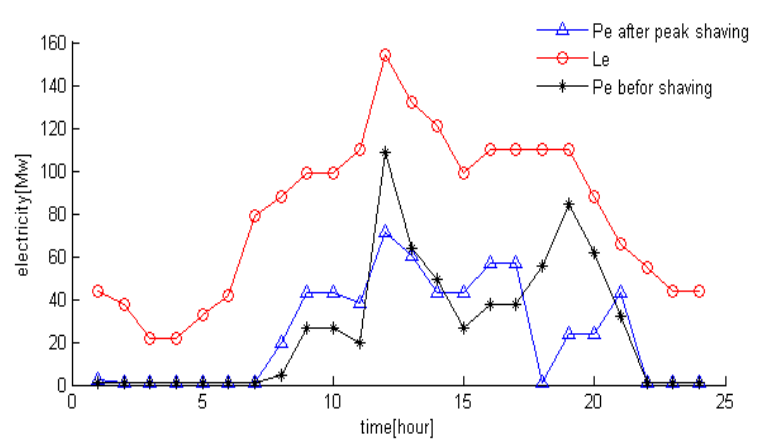

Fig.6. Pe after and before including peak shaving factor in the objective function

If the gas price in previous conditions had more valid intervals to change as a result the load curve could get smoother.

Note that in these case studies energy consumption price is fixed after and before peak shaving.

\section{Conclusion}

In this paper a mathematical model for a system with multicarrier energy carrier is proposed. Based on this model an optimized consumption of each energy carrier, natural gas and electricity, are determined by considering peak shaving that has a very significant effect to reduce risk in an electricity network.

Existence of CHP in an energy hub and with high penetration level creates this opportunity to use natural gas price as a motivation factor to shift the consumption of electricity in high load durations to the natural gas network.

Natural gas pricing policy is done by Genetic Algorithm (GA) And the best pricing is determined consequently.

\section{Acknowledgement}

The authors would like to thank National Institute of Elite of Iran and Institute and Power Research unit of Tavanir for financial and technical support during this research.

\section{References}

[1] N. Hatziargyriou, H. Asano, R. Iravani, and C. Marnay, "Microgrids," in IEEE Power and Energy Magazine, vol. 5, iss. 4, pp 78-94, July-Aug. 2007.

[2] G. Venkataramanan, and C. Marnay, "A larger role for microgrids," in IEEE Power and Energy Magazine, vol. 6, iss. 3, pp 78-82, May-June 2008.

[3] B. Lu and M. Shahidehpour, "Unit commitment with flexible generating units,” IEEE Trans. Power Syst., vol. 20, no. 2, pp. 1022-1034, May 2005.

[4] A. Smith, "Multi-criteria decision making approach to optimization of fuel-mix choice for electric power generation under environmental impact constraints," M.S. thesis, Dept. Civil Environ. Eng., Carleton Univ., Ottawa, ON, Canada, Aug. 2000.

[5] R. Frik and P. Favre-Perrod, "Proposal for a multifunctional energy bus and its interlink with generation and consumption," diploma thesis, Power Systems and High Voltage Laboratories, ETH, Zurich, Switzerland, 2004.

[6] J. Carpentier, “Optimal power flows,” Int. J. Elect. Power Energy Syst., vol. 1 , no. 1, pp. 3-15, 1979. 
[7] P. J. Wong and R. E. Larson, "Optimization of natural-gas pipeline systems via dynamic programming," IEEE Trans. Autom. Control, vol.AC-13, no. 5, pp. 475-481, Oct. 1968.

[8] A. Benonysson, B. Bohm, and H. F. Ravn, "Operational optimization in a district heating system,” Energy Convers. Manage., vol. 36, no. 5, pp. 297-314, 1995.

[9] G. Koepple and G. Anderson, "The influence of combined power, gas and thermal networks on the reliability of supply," The sixth world energy system conference, Torino, Italy, 2006.

[10] M. Geidl, "Integrated modeling and optimization of multicarrier energy systems", Power Systems Laboratory, ETH Zurich, 2007

[11] M. Geidl, "A greenfield approach for future power systems," in Proc. Cigre Session 41, Paris, France, 2006.

[12] M. Shahidehpour, Y. Fu, and T. Wiedman, "Impact of natural gas infrastructure on electric power systems," Proc. IEEE, vol. 93, no. 5, pp. 1042-1056, May 2005

[13] I. Bouwmans and K. Hemmes, "Optimising energy systems-Hydrogen and distributed generation," in Proc. 2nd Int. Symp. Distributed Generation: Power System Market Aspects, Stockholm, Sweden, 2002.

[14] S. An, Q. Li, and T. W. Gedra, "Natural gas and electricity optimal power flow," in Proc. IEEE Power Eng. Soc. Transmission Distribution Conf., Dallas, TX, 2003.

[15] M. Geidl, “Optimal Power Flow of Multiple Energy Carriers" IEEE transactions on power systems, VOL.22, NO. 1, February 2007

[16] M. Geidl, G. Koeppel, P. Favre-Perrod, B. Klöckl, G. Andersson, K. Fröhlich, "Energy Hubs for the futures", published in IEEE Power \& Energy Magazine, 5(1):24-30, 2007

[17] H. M. Groscurth, T. Bruckner, and R. Kümmel, "Modeling of energy service supply system”, Energy, vol. 20, no. 9, pp. 941-958, 1995.

[18] I. Bouwmans and K. Hemmes, "Optimising energy systems-Hydrogen and distributed generation," 2nd Int. Symp. Power System Market Aspects, Stockholm, 2002

[19] R. H. Lasseter and P. Piagi, "Microgrid: A conceptual solution," in Proc. IEEE 35th Annu. Power Electronics Specialists Conf. (PESC), Aachen, Germany, 2004.

[20] J. Hernandez-Santoyo and A. Sanchez-Cifuentes, "Trigeneration: An alternative for energy savings,” Appl. Energy, vol. 76, no. 1-3, pp. 219227, 2003.

[21] A. Prasai, A. Paquette, Y. Du, R. Harley and D. Divan “ Minimizing Emissions in Microgrids While Meeting Reliability and Power Quality Objectives", The 2010 International Power Electronics Conference. 